\title{
Do Derivatives hinder the Financial Contagion? A case Study of Developed Countries' Stock Markets
}

\author{
SAEED RASEKHI* and NASIM NABAVI
}

${ }^{1}$ Department of Economics, University of Mazandaran, Iran.

\begin{abstract}
The main purpose of this study is to test the effect of the derivative instruments on financial contagion in developed countries including France, Germany, South Korea, Spain, the Netherlands and the United Kingdom, considering the United States as the source of the crisis. Therefore, at first, existence of the contagion in the markets was investigated using the ARMA-GARCH-COPULA method, and then, the effect of the derivative instruments on the contagion for the selected countries was examined during the time period 01: 2007: to $08: 2018$. The results confirm the negative effect of the derivatives on the contagion.
\end{abstract}

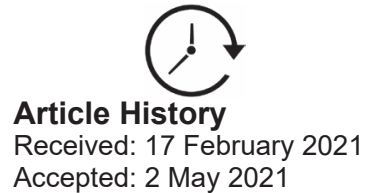

Keywords

Copula Function;

Derivatives;

Developed Countries;

Financial Contagion;

Stock Market.

\section{Introduction}

The 2008 financial crisis in the United States went bankrupt the Lehman Brothers Company, one of the largest commercial banks in the country. The effects of the crisis was quickly shifted to Europe, Asia and Latin America, and in a short time, global financial markets were faced with a sharp decline in exchange rate, commodities and stock value. The expansion of the negative effects of the event to the financial markets of a number of countries was named as the financial contagion of Lehman brother's company bankruptcy at the same time (Wiggins, et al. ${ }^{41}$

Although extensive research has been carried out on the complex phenomenon of contagion, but this conception has not defined precisely and comprehensively. Generally, contagion referring to the transfer of devastating effects of the crisis, from one country to another or a group of countries, is accompanied by an co-movement in stock value, exchange rate and capital flow. The contagion can occur for two reasons and has two distinct concepts (Masson, ${ }^{19}$ Wolf ${ }^{39}$ and Pritsker ${ }^{25}$ ). First, contagion is the spillover due to the usual interdependence among countries. Such interdependence means that the transfer of shocks is due to the real and financial relations among countries. This comovement does not mean pure contagion. Because it reflects a normal dependency that may intensify during a crisis period in a country (Pritsker, ${ }^{25}$ ). Second, contagion is not only an increase in co-movement based on economic principles. This pure contagion involves a purely financial crisis that is not related to changes observed in macroeconomic conditions and is merely a result of the behavior of investors or other financial agents.

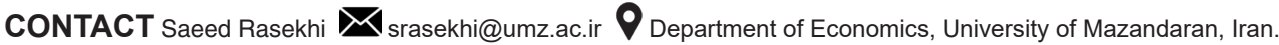

\section{(c) (i)}

(C) 2021 The Author(s). Published by Enviro Research Publishers.

This is an 2 Open Access article licensed under a Creative Commons license: Attribution 4.0 International (CC-BY).

Doi: http://dx.doi.org/10.12944/JBSFM.02.01.10 
According to this definition, the crisis in a country and the price volatility in financial markets may lead investors to with draw their capital from many markets because of risk and uncertainty (Masson, ${ }^{19}$ ).

Hence, the financial instruments of risk management to reduce volatility and contagion are important. In this regard, derivative instrument is important as a method to hedge and reduce volatility in financial markets, especially stock markets. Derivative instrument is a kind of financial oneand its value is derived from a stock or a portfolio (Mallikarjunappa and Afsal, ${ }^{20}$ ). These instruments are the most important tools for price discovery, portfolio diversification, and hedge in financial markets around the world (Pilarand Rafael, ${ }^{23}$ ).

There are two different views on the effectiveness of a derivative instrument on the volatility of financial markets. In the first one, derivative instrument increases the volatility of financial markets (Stein and Stein, ${ }^{36}$ ) and based on the second view which is more dominant, these types of transaction screate less volatilities and, consequently, the more stability of markets (Powers, ${ }^{22}$ Schwarz ${ }^{33}$ ).

The main purpose of this paper is to examine the effect of derivatives on the contagion and in this framework we show that the contagion may be mitigated by using the derivatives. Besides, the review of historical financial crises especially in the United States with long-run effects on other countries has some lessons for the future since they have similar global causes, effects and solutions. As a solution, the spread of derivatives in financial markets may have an insulating effect which is the present research hypothesis.

Based on the hypothesis, this study examines the effect of a derivatives on the stock market contagion of France, Germany, South Korea, Spain, the Netherlands and the United Kingdom during the period of 01:2007 to $08: 2018$ using monthly stock index and futures contract of the stock index. For this purpose, the United State was considered as the source of the financial crisis in 2008 . To test the hypothesis of the negative effect of the derivative instrument on the stock market contagion, at first, the dependency parameter for each pair of series (United States/ France, United States/ Germany, etc.) was estimated using the Copula function, and then, the hypothesis was examined with the null one of the non-negative effect of the derivative instrument on stock market contagion.

\section{Theoretical and Emprical Background}

Although most researchers agree on the phenomenon of post-crisis contagion, there is still no precise definition of financial contagion. Seth and Panda ${ }^{43}$ has classified the contagion and given several definitions and methods for capturing it and in this case, it has clarified that the contagion is a wide conception. Specifically, the paper has mentioned the categories of contagion definitions of the World Bank group which are broad, restrictive and very restrictive definitions (figure 3 of this paper). There is also no agreement to choose the best method for measuring contagion (Echen green and Mody $^{6}$ ). The World Bank ${ }^{40}$ has proposed three definitions of contagion; broad, restrictive and very Restrictive ones.In a broad definition, Contagion is the cross-country transmission of shocks or the general cross-country spillover effects. Of course, Contagion can occur both during good and bad times and in this framework, it is different from a crisis. In a restrictive definition, Contagion is the transmission of shocks to other countries and it means the cross-country correlations, beyond any fundamental link among the countries and beyond common shocks. This definition is usually referred as excessco-movements, commonly explained by herding behavior and in a very restrictive definition, Contagion occurs when cross-country correlations increase during crisis times relative to correlations during tranquil times $\left(\right.$ Gandolfo $\left.^{8}\right)$.

It is very difficult to determine a proper mix of financial and real, and even political principles in order to measure the contagion. One of the methods of measuring the contagion is to measure the correlation of markets in the pre-crisis and the crisis period and then test them statisticallly. Specifically, there will be a sign of financial contagion, if the correlation coefficient between markets is increased. A wide range of studies has tested the existence of contagion in financial markets by a simple correlation coefficient between these markets. The ARCH and GARCH models are very useful in this regard. Sunsequent studies have observed the contagion as a nonlinear phenomenon and employed Copula functions to study its effects (Rodrigue ${ }^{26}$ ). 
Derivative instruments play a very important role in the risk management for investors and managers of investment funds. There are two different views on the effect of these financial instruments on volatilities in the literature. In the first view, these types of transactions are one of the reasons for the volatilities of spot markets and, as a result, market instability (Cox; ${ }^{5}$ Figlewski; ${ }^{7}$ Steinand Stein ${ }^{36}$ ). According to the first view, the activity of traders with a little money or stock in a market with a high level of leverage effect can reduce the quality of information in the market (Figlewski ${ }^{7}$ ). Against this view, some studies have proved that derivative instruments did not increase the risk and market volatility (McLear and Chang; ${ }^{18}$ Rossi and Daigler ${ }^{28}$ ). Based on the second view, the financial instruments are the reasons for falling volatilities and, consequently, the stability of markets (Powers; ${ }^{22}$ Schwarz ${ }^{33}$ ). The empirical results are also different and ambiguous. But, most results show that derivative trading did not increase the price fluctuations in spot markets in the long run.

Shembagaraman ${ }^{32}$ by examining the Indian stock market concluded that by introducing the derivatives (futures), the volatilities changed qualitatively and quantitatively. Boyer and Loretan ${ }^{1}$ used a market model to find fluctuations before and after the introduction of futures, and they did not find any evidence to increase volatility after the introduction of derivative instruments. Also, Mallikarjunappa and $\mathrm{Afsa}^{20}$ did not find any evidence of stability or instability after the introduction of futures and option contracts on the Indian stock index. Pilar and Rafael ${ }^{23}$ investigated the effect of derivative instruments on the instability of the return on the assets in the Spanish stock market and using the GARCH model and the Exponential GARCH $(E G A R C H)$ model. They showed that the conditional variance of the return reduced after using the derivatives. In addition, the use of derivative instruments in Spain reduced the uncertainty and increased the liquidity as well as market efficiency. Shenbagaraman ${ }^{34}$ tested the effect of the futures and option son stock market volatilities. The results showed that the existence of derivatives did not have a significant effect on the market volatility during the whole period. Jacobsen ${ }^{14}$ by using the ARMA and the GARCH models showed that there is astrong and positive relationship between unexpected speculative shock and stock price volatility for the whole period. Also, the results indicated thatthe derivatives affected volatilities and speculators as market players. Rayand Panda ${ }^{27}$ examined the effect of financial derivatives on stock market volatilities in India. The results showed that the volatilities in the period of introduction of the derivatives increased as compared with the previous periods, with more continuity, and therefore the stock market has less coherence than the periods before using of the derivatives. Singh and Tripathi ${ }^{32}$ by examining the effect of derivative instruments on the Indian currency market fluctuations, by using the GARCH model, showed that the existence of derivatives led to a decrease in foreign exchange market volatility in India. The results also indicated the more importance of recent news in the market volatilities, and decreasing the effect of the continuation of the old news, with the introduction of futures.

Bae et al. ${ }^{3}$ showed that the contagion of Latin America to other parts of the world was higher than that from Asia to other parts of the world. Kuusk and Tripathi ${ }^{15}$ with the review of the financial contagion in US crisis in 2008 between the United States and the Baltic states, indicated that there was a finantioal contagion from the United States to the Baltic states. Imen and $\mathrm{Abidi}^{11}$ tested the contagion and showeda significant increase in the dynamic correlation between developed and developing stock market returns by using the $\mathrm{GARCH}$ model. The results indicated a high degree of financial integration among the studied countries, especially during the financial crisis. Mollah and Zafirov ${ }^{17}$ investigated the global financial crisis contagion and revealed that there were the contagion in 46 countries of 63 countries. In these countries, there was a significant increase in the correlation coefficient of stock market returns during the financial crisis as compared with the pre-crisis period. Based on this reseach, although the crisis originated from the United States, it immediately spread to other global markets. Shastri ${ }^{37}$ investigated the correlation between the bond and the stock markets in developing and developed countries with the Copula function. The results showed that these markets in the studied countries have co-movements.

According to the literature, the derivatives have a negative effect on the volatility, but there are few studies over the effect of derivatives on the contagion. Based on this narrow literature, on one hand, the derivatives have a positive effect on the 
Vol. 02(1 \& 2) 89-101 (2021)

contagion since speculators use the derivatives for their benefits and in this case, the market may be volatile and contagious. On the other hand, the derivatives as hedging instruments immune the dealers against the volatilities and based on this feature as well as the nature of these types of transactions which are effective on the value date based on the present-determined forward rate, the volatility and the contagious phenomenon may be alleviated by using and strengthening of the derivatives. Furthermore, through wake up calls mechanism, the crisis has spread to other countries without significant relations with the origin of the crisis since bad news from the crisis has negative effect on the investors' attitudes and actions. By expanding the use of derivatives, investors are investing more confidently, therefore effect of bad news and financial contagion is reducing.

\section{Methodology}

Every econometric methodology depends on some statistical characteristics especially regarding to the statistical distribution of variables as well as the purpose of the research. In the study of contagion, the Copula function with different distributions is more suitable than other methods. This method is not limited toa specific distribution such as normal one which is not correct for skewed distributions. As shown in the litrature, Copula is suitable for modeling the dependence and co-movement of several stochastic variables and this helps researchers to build the joint distribution of these variables with specified statistical features. Using some proxies such as simple correlations for the dependency may create biased results especially with variable variance and mean.

The GARCH model was proposed by Bollersley. ${ }^{2}$ Many researchers developed this model and presented a variety of $\mathrm{GARCH}$ models in the following years. In this framework, the model ARMA $(p, q)-G A R C H(r, s)$ is presented as follows:

$$
\begin{aligned}
& y_{t}=x_{t}^{\prime} \gamma+u_{t},(t=1,2, \ldots, T) \\
& u_{t}=\sum_{j=1}^{p} \phi_{j} u_{t-j}+\varepsilon_{t}+\sum_{j=1}^{q} \theta_{j} \varepsilon_{t-j} \\
& \sigma_{t}^{2}=\omega+\sum_{j=1}^{r} \alpha_{j} \varepsilon_{t-j}^{2}+\sum_{j=1}^{r} \beta_{j} \sigma_{t-j}^{2}
\end{aligned}
$$

Where $\gamma$ is the regression coefficient; $\sigma_{t}^{2}$ is the conditional variance of $\varepsilon_{t} ; \theta_{j}$ and $\phi_{j}$ are $\operatorname{ARMA}(\mathrm{p}, \mathrm{q})$ model parameters; $\beta_{j}$ and $\alpha_{j}$ are GARCH $(\mathrm{r}, \mathrm{s})$ model parameters.
The Copula ${ }^{2}$ function is a method for modeling the dependencies of several random variables. According to Sklar ${ }^{29}$ theory, Copulas are the mechanism which allows to isolate the dependency structure in a multivariate distribution $\left(\mathrm{Schmidt}^{35}\right)$. An important tool for the Sklar theorem is related to the main result of Fisher's random number generation theory, which states that if $X$ is a random continuous variable with a distribution function $F$, then $U=F(X)$ has a uniform distribution in the interval $[1,0]\left(\right.$ Patton $\left.^{24}\right)$. According to Sklar theory, $F$ is a d-dimensional distribution function with margins $F_{1} . F_{2}, \ldots, F_{d}$ and $\mathrm{C}$, d-dimensional copula for all $\mathrm{x}$ in $\bar{R}^{n}\left(\right.$ Nelsen $\left.^{21}\right)$.

$F\left(x_{1}, x_{2}, \ldots, x_{d}\right)=C\left(F_{1}\left(x_{1}\right), \ldots, F_{d}\left(x_{d}\right)\right)$

copula function is:

$$
C\left(u_{1}, \ldots, u_{d}\right)=F\left(F_{1}^{-1}\left(u_{1}\right), \ldots, F_{d}^{-1}\left(u_{d}\right)\right)
$$

Where $F_{i}^{-1}$ is an inverse function of the marginal distribution and $U \sim$ Unif $(0,1)\left(\right.$ Nelsen $\left.^{21}\right) . C\left(u_{1}, \ldots, u_{d}\right)$ is non-decreasing in each component, $u_{i}$ and the $\mathrm{i}^{\text {th }}$ marginal distribution is obtained by setting $u_{i}=1$ for $j \neq i$ and since it is uniformly distributed $C(1, \ldots, 1$, $\left.u_{i}, 1, \ldots 1\right)=u_{i}\left(\operatorname{Haugh}^{9}\right)$.

Rank correlations (Kendall's $\tau$ and Spearman's $\rho$ ) are also useful in measuring the dependence structure between the copulas (Siedlecki and $\mathrm{Papla}^{30}$ ). Kendall's $\tau$ is defined as follows, and the parameters are directly obtained from the copula function (Hortaand Vieira ${ }^{10}$ )

$$
\tau_{\text {Kendall }}\left(X_{1}, X_{2}\right)=1-4 \int_{0}^{1} \int_{0}^{1} \frac{\partial C\left(u_{1}, u_{2}\right)}{\partial u_{1}} \frac{\partial C\left(u_{1}, u_{2}\right)}{\partial u_{2}} d u_{1} d u_{2}
$$

Different types of copula in literature, and in the studies of Nelsen ${ }^{21}$ and Joe ${ }^{13}$ were used to model dependence. But Gumbel, Frank, Clayton and $\mathrm{t}$-Student Copulas havebeen mostly used in financial and insurance market studies (Trivedi and Zimmer ${ }^{38}$ ). Gumbel Copula has a low tail dependence and high tail independence.

$C_{G}(u, v ; \delta)=\exp \left\{-\left[(-\ln u)^{\delta}+(-\ln v)^{\delta}\right]^{\frac{1}{\delta}}\right\}, \quad \delta \in[1, \infty)$

Clayton Copula has a low tail dependence and high tail independence. 
$C_{c l}(u, v ; \theta)=\left\{u^{-\theta}+v^{-\theta}-1\right\}^{\frac{-1}{\theta}}, \theta \geq 0$

Frank Copula is indicated by a high and low tail dependence.

$C_{f}(u, v ; \alpha)=-\frac{1}{\alpha} \ln \left[1+\frac{\left(\mathrm{e}^{-\alpha u}-1\right)\left(\mathrm{e}^{-\alpha v}-1\right)}{\mathrm{e}^{-\alpha}-1}\right], \quad \alpha \in[0, \infty)$

t-Student CopulaCopula is symmetric and shows the tail dependence

$$
C(u, v ; v, \rho)=\int_{\infty}^{\hbar_{v}^{-1}(u)} \int_{\infty}^{\hbar_{v}^{-1}(v)} \frac{1}{2 \pi \sqrt{\left(1-\rho^{2}\right)}}\left\{1+\frac{s^{2}-2 \rho s t+t^{2}}{v\left(1-\rho^{2}\right)}\right\}^{\frac{-v-1}{2}} d s d t . .
$$

The coefficient of tail dependence is equal to:

$\lambda_{1}=\lambda_{u}=2\left[1-t_{v+1}(\sqrt{(v+1)(1-\rho) /(1+\rho)})\right]$

Clayton and Gumbel Copulas cannot be used to model negative dependencies. But the use of the above copulas helps solve the problem, since there usually is a positive dependence between the returns on the stock indices. Frank Copula is symmetric, and has advantages as compared with the Gumbel, Clayton, and t-Student Copulas, because it offers a simpler estimate of the dependence structure due to its simple analytical form. It is also suitable for variables with poorly dependence structure (Trivedi and Zimmer ${ }^{38}$ ).

The data of this research, stock and futures indices are as follows: FTSE100 stock market index ofthe 100 listed companies in London Stock Exchange, DAX German Stock Index, AEX Netherlands Stock Index, KOSPI200 Index of all traded stock on the South Korean Stock Exchange, IBEX35 index of the 35 largest companies on the Spanish Stock
Exchange, and the S \& P500 index of the 500 largest companies on the United States Stock exchange.

It is necessary to determine the crisis period to investigate the effect of a derivative instrument on the contagion of stock markets in developed countries. Also, the stock returns must be calculated using the data before software computations. Stock returns are equal to the natural logarithmic difference of two successive stock indexes:

$R_{c}=1 \mathrm{n}\left(P_{i t} / P_{i t}-1\right)$

$P_{i t}$ showsthe stock index and $R_{i t}$ the return on stock index.

\section{Estimation Results}

Descriptive statistics of the data used in the research are presented in tables (1) and (2). Based on these tables, distributions of the return of French stock index (RCAC40) and the UK futures (FFTSE100) are closer to the normal distribution.

Stationarity and non-stationarity can have a serious effect on the properties of a given time series $\left(\right.$ souri $\left.{ }^{31}\right)$. For this reason, the unit root test of the Dickey-Fuller was performed for each time series. The results are presented in tables 3 and 4 . The results of tables 3 and 4 show that all studied variables) Stock Returnsand futures) are stationary.

Given that $\mathrm{H}_{0}$ in the $\mathrm{ARCH}$ effect test is homoscedasticity of the residuals, based on the results of table 5, the statistics are large and in the critical area. Also, the probabilities for the statistics are less than 0.05 . Consequently, the $H_{0}$ is rejected and the hypothesis of the existence of the $\mathrm{ARCH}$ effect is not rejected. Therefore, considering the

Table 1: Descriptive statistics of return on stock indices

\begin{tabular}{lccccccc}
\hline RSP500 & RIBEX35 & RFTSE100 & RDAX & RKOSPI200 & RCAC40 & RAEX & \\
\hline 0.0058930 & -0.001276 & 0.002222 & 0.005843 & 0.005007 & 0.001035 & 0.002195 & Mean \\
0.0102360 & 0.001468 & 0.005319 & 0.009852 & 0.006687 & 0.001953 & 0.009783 & Median \\
0.1077230 & 0.166245 & 0.084522 & 0.167621 & 0.137171 & 0.125567 & 0.111735 & Maximum \\
-0.169425 & -0.170330 & -0.130248 & -0.191921 & -0.209620 & -0.135173 & -0.197147 & Minimum \\
-0.778020 & -0.067773 & -0.437617 & -0.503357 & -0.542259 & -0.352362 & -0.978079 & Skewness \\
4.9234020 & 3.684409 & 3.469477 & 4.538322 & 5.404606 & 3.131940 & 5.666992 & Kurtosis \\
\hline
\end{tabular}

Source: Present Research Findings based on Investing Statistical Database ${ }^{42}$ 
RASEKHI \& NABAVI, Journal of Business Strategy, Finance and Management,

Vol. 02(1 \& 2) 89-101 (2021)

Table 2: Descriptive statistics of futures

\begin{tabular}{lcccccc}
\hline FAEX & FKOSPI200 & FCAC40 & FDAX & FFTSE100 & FIBEX35 & FSP500 \\
\hline 406.3534 & 247.0129 & 4323.904 & 8462.682 & 6139.005 & 10234 & 16 \\
405.45 & 250.8 & 4340.25 & 7892.5 & 6218.25 & & \\
571.1 & 334.95 & 6090 & 13222 & & & \\
215.9 & 137 & 2701 & & & & \\
0.02715 & -0.388254 & & & & & \\
1.92584 & & & & & & \\
\hline
\end{tabular}

Source: Present Research Findings based on Investing Statistical Database ${ }^{42}$

Table 3: Dickey-Fuller Unit Root Test Results for Returns of Stock Indices

\begin{tabular}{lcccc}
\hline Symbol & Dickey-Fuller (DF) & P-Value & Null Hypothesis & Country \\
\hline RKOSPI200 & -11.12261 & 0.00000 & Lack of unit root & South Korea \\
RSP500 & -9.99774 & 0.00000 & Lack of unit root & United states \\
RFTSE100 & -12.05112 & 0.00000 & Lack of unit root & England \\
RDAX & -9.486566 & 0.00000 & Lack of unit root & Germany \\
RAEX & -10.50653 & 0.00000 & Lack of unit root & Netherlands \\
RCAC40 & -10.44505 & 0.00000 & Lack of unit root & France \\
RIBEX35 & -11.13608 & 0.00000 & Lack of unit root & Spain \\
\hline
\end{tabular}

Source: Present Research Findings based on the Output of Eviews Software

Table 4: Dickey-Fuller unit root test results for futures

\begin{tabular}{lcccc}
\hline Symbol & Dickey-Fuller (DF) & P-Value & Null Hypothesis & Country \\
\hline FKOSPI200 & $11.72244-$ & 0.00000 & Lack of unit root & South Korea \\
FSP500 & $10.6181-$ & 0.00000 & Lack of unit root & United States \\
FFTSE100 & $12.6287-$ & 0.00000 & Lack of unit root & England \\
FDAX & $9.39485-$ & 0.00000 & Lack of unit root & Germany \\
FAEX & -11.00865 & 0.00000 & Lack of unit root & Netherlands \\
FCAC40 & $10.46078-$ & 0.00000 & Lack of unit root & France \\
FIBEX35 & $10.64336-$ & 0.00000 & Lack of unit root & Spain \\
\hline
\end{tabular}

Source: Present Research Findings based on the Output of Eviews Software

existence of heteroscedasticity in the model, the $\mathrm{GARCH}$ model is used for modeling dependence.

The ARMA-GARCH model was estimated for each country and the filtered returns extracted before estimating the model and testing the hypothesis of the research. Then, the proper distribution of filtered returns was identified by Akaike criteria. In the folowing, the Copula function was estimated and the
Kandell rank correlation coefficient was calculated for each pair of series. In the end, the presence of contagion was examinedfor selected countries. The null hypothesis is the absence of financial contagion:

$$
\left\{\begin{array}{l}
H_{0}=\Delta \tau=\tau_{\text {crisis }}-\tau_{\text {pre-crisis }} \leq 0 \\
H_{1}=\Delta \tau=\tau_{\text {crisis }}-\tau_{\text {pre-crisis }}>0
\end{array}\right.
$$


Vol. 02(1 \& 2) 89-101 (2021)

It should be noted that the starting point of the crisis is October 2008, but we assumed that the crisis period has begun since September 2008 for more confidence in modeling. Therefore, the precrisis period is from January 2007 to August 2008 (Hortaand Vieira $\left.{ }^{10}\right)$. The hypothesis test results are presented in table 6 .

Table 5: ARCH-LM test results

\begin{tabular}{|c|c|c|}
\hline$P$ - value & $\begin{array}{l}\text { Calculated } \\
\text { statistics }\end{array}$ & Countries \\
\hline 0.000 & 452.8428 & $\mathrm{~F}$ \\
\hline 0.000 & 97.68324 & Obs ${ }^{*}$-Squared S \\
\hline 0.000 & 1047.749 & $\mathrm{~F}$ \\
\hline 0.000 & 111.0673 & Obs*R- \\
\hline 0.000 & 9.348262 & $\mathrm{~F}$ \\
\hline 0.000 & 101.8062 & \\
\hline 0.000 & 497.7478 & \\
\hline 0.000 & 99.59007 & \\
\hline 0.000 & 466.1 & \\
\hline \multicolumn{3}{|l|}{0.000} \\
\hline \multicolumn{3}{|l|}{0.000} \\
\hline 0.0 & & \\
\hline
\end{tabular}

Source: Present Research Findings based on the Output of Eviews Software

Table 6: Results of the existence of financial contagion

\begin{tabular}{|c|c|c|}
\hline$\Delta \tau$ & p- value & Country \\
\hline 0.07156 & 0.015 & South Korea/ United States \\
\hline 0.02324 & 0.021 & England/ United States \\
\hline 0.1848 & 0.031 & Germany / United States \\
\hline 0.1397 & 0.055 & Netherlands / United States \\
\hline 0.0073 & 0.019 & France / United States \\
\hline 0.15625 & 0.021 & Spain / United States \\
\hline
\end{tabular}

Source: Present Research Findings based on the Output of Model Risk Software

$\Delta \tau$ indicates the difference between the Kendall rank correlation coefficient of crisis and non-crisis periods. According to table 6 , the null hypothesis is rejected with a probability of $95 \%$ and the hypothesis of the existence of contagion between the pairs of countries is accepted. Consequently, the hypothesis of the negative effect of the futures on stock market contagion is tested. For this, the futures is introduced in the ARMA-GARCH model only considering the crisis period. In the end, the Copula parameter and the Kendell rank correlation coefficient after introducing the futures are compared with the Copula parameter and the Kendell correlation coefficient before using the derivatives. Table 7 presents the results of correlation and partial correlation coefficients.

Based on the results, the model of all countries except South Korea is ARMA $(0,0)-\operatorname{GARCH}(1,1)$. The futures was entered as an independent variable in the ARMA-GARCH model to estimate the ARMAGARCH model.Then, the filtered returns were extracted like the process of estimating financial contagion, before the introduction of the derivative instrument, which is the residual of the estimated model above. The distribution functions were determined for each series (filtered returns). The type of distribution function of the filtered returns as input was used to estimate the copula and calculate the Kendell rank correlation coefficient.

As shown in table 9, the filtered returns distribution for the United States, Germany, South Korea, England and Spain is logistic one. Furthermore, the distribution of the filtered returns for the Netherlands and France is normal. Consequently, Copula is estimated to examine the dependence structure of each pair of series according to the specified distributions for each series, and the Akaike criterion is also used to select the appropriate copula. Estimated copulas parameters with Akaike statistics are presented in tables 10 and 11 .

Comparison of Copula parameters before introducing the future contract during the crisis period with Copula parameters after introducing the future contract during the crisis period showed that the Copula parameter reduced after the introduction of the futures in all studied countries. The selection of the appropriate copula for each pair of series is based on the Akaike criterion and the results are presented in table 12.

As stated, in addition to the copula parameters, Kendall's correlation coefficient is the other method to examine the dependence. If Kendall's rank correlation coefficient in the crisis period after introducing the futures than before introducing the 
Vol. 02(1 \& 2) 89-101 (2021)

future contracts reduced, it can be claimed that the future contracts reduces the co-movements between stock markets and the effects of contagion. Table 13 shows the rank correlation coefficients for the pair of series that the presence of the contagion is not rejected in them after introducing of the futures.
Comparison of table 13 and 14 shows that the rank correlation coefficient between pair of series has been reduced despite the futures, which is indicative of the negative effect of the futures on the co-movement and the contagion between the stock markets of countries with the US stock market.

Table 7: Results of correlation coefficients

\begin{tabular}{lcc}
\hline stock return index & \multicolumn{1}{c}{ Model } & country \\
& ARMA(p,q)-GARCH(r,s) & \\
RKOSPI200 & $\operatorname{ARMA}(3,3)-\operatorname{GARCH}(1,1)$ & South Korea \\
RSP500 & $\operatorname{ARMA}(0,0)-\operatorname{GARCH}(1,1)$ & United States of America \\
RFTSE100 & $\operatorname{ARMA}(0,0)-\operatorname{GARCH}(1,1)$ & England \\
RDAX & $\operatorname{ARMA}(0,0)-\operatorname{GARCH}(1,1)$ & Germany \\
RAEX & $\operatorname{ARMA}(0,0)-\operatorname{GARCH}(1,1)$ & Netherlands \\
RCAC40 & $\operatorname{ARMA}(0,0)-\operatorname{GARCH}(1,1)$ & France \\
RIBEX35 & $\operatorname{ARMA}(0,0)-\operatorname{GARCH}(1,1)$ & Spain \\
\hline
\end{tabular}

Source: Present Research Findings based on the Output of Model Risk Software

Table 8: Distribution of Filtered Returns during Crisis, after Introducing the futures

\begin{tabular}{llllll}
\hline Logistic & Normal & Student & Ext-value min & Ext-.value max & index \\
\hline-425.388 & -421.422 & -228.79 & -343.84 & -166.31 & RKOSPI200 \\
-432.422 & -428.35 & -228.77 & -405.656 & -148.535 & RSP500 \\
-435.94 & -435.92 & -228.76 & -406.81 & -172.17 & RFTSE100 \\
-373.44 & -370.018 & -228.911 & -353.058 & -65.153 & RDAX \\
-356.71 & -394.045 & -228.85 & -361.62 & -94.558 & RAEX \\
-299.5 & -383.401 & -228.87 & -363.388 & -151.41 & RCAC40 \\
-342.688 & -339.811 & -229.009 & -252.928 & -105.378 & RIBEX35 \\
\hline
\end{tabular}

Source: Present Research Findings based on the Output of Model Risk Software

Table 9: distribution of filtered returns after introducing the futures

\begin{tabular}{lc} 
Index & Proper distribution \\
RKOSPI200 & Logistic \\
RSP500 & Logistic \\
RFTSE100 & Logistic \\
RDAX & Logistic \\
RAEX & Normal \\
RCAC40 & Normal \\
RIBEX35 & Logistic \\
\hline
\end{tabular}

Source: Present Research Findings based on the Output of Model Risk Software 

Vol. 02(1 \& 2) 89-101 (2021)

Table 10: Copula Estimation Result after the Crisis and before introducing of futures

\begin{tabular}{|c|c|c|c|c|c|c|c|}
\hline Index & Criterion & Clayton & Frank & Gumbel & Normal & t- student & Country \\
\hline \multirow[t]{3}{*}{ C-RSP500/C-RKOSPI200 } & MLE fit & 1.05 & 3.46 & 1.52 & 0.65 & $6,0.65$ & USA / Sout \\
\hline & $\mathrm{AIC}$ & 42.139 & 30.48 & 46.63 & 44.003 & 44.52 & \\
\hline & LL & 23.12 & 17.29 & 25.36 & 23.01 & 24.31 & \\
\hline \multirow[t]{3}{*}{ C-RSP500/C-RFTSE100 } & MLE fit & 2.23 & 6.45 & 2.16 & 0.81 & $5,0.8$ & \\
\hline & $\mathrm{AIC}$ & -98.06 & -83.27 & -106.29 & -100.21 & & \\
\hline & LL & 51.082 & 43.68 & 55.19 & 51.1 & & \\
\hline \multirow[t]{3}{*}{ C-RSP500/C-RDAX } & MLE fit & 2.27 & 6.36 & 2.13 & & & \\
\hline & AIC & -92.76 & $-80.74-99$ & & & & \\
\hline & LL & 48.43 & 42.42 & & & & \\
\hline \multirow[t]{3}{*}{ C-RSP500PC-RAEX } & MLE fit & 1.799 & 5 & & & & \\
\hline & AIC & 72.3 & & & & & \\
\hline & LL & & & & & & \\
\hline C-RSP500/C-RCAC40 & $M L$ & & & & & & \\
\hline C-RSP500/C- & & & & & & & \\
\hline
\end{tabular}

Source: Present Research Findings based on the Output of Model Risk Software

Table 11: Copula Estimates Result in the crisis period and after the introducing futures

\begin{tabular}{llllllll}
\hline Index & criterion & Clayton & Frank & Gumbel & Normal & t- Student & Country \\
\hline RSP500/ RKOSPI200 & MLE fit & 0.89 & 3.03 & 1.44 & 0.55 & $5,0.55$ & USA/South Korea \\
& AIC & 21.67 & 23.02 & 29.74 & 35.13 & 34.84 & \\
& LL & 12.89 & 13.56 & 16.92 & 18.58 & 19.47 & \\
RSP500/ RFTSE100 & MLE fit & 2.23 & 6.27 & 2.11 & 0.79 & $7,0.79$ & USA/ England \\
& AIC & 84.37 & 81.05 & 98.47 & 98.43 & 98.87 & \\
RSP500/ RDAX & LL & 44.23 & 42.57 & 51.29 & 50.23 & 51.49 & \\
& MLE fit & 2.26 & 6.35 & 2.08 & 0.57 & $6,0.57$ & USA/ Germany \\
& AIC & 90.72 & 83.58 & 100.58 & 93.42 & 96.07 & \\
RSP500/RAEX & LL & 47.41 & 43.84 & 52.34 & 47.72 & 50.08 & \\
& MLE fit & 1.77 & 5.23 & 1.88 & 0.73 & $4,0.73$ & USA/ Netherlands \\
& AIC & 72.731 & 63.03 & 79.85 & 73.34 & 79.52 & \\
RSP500/ RCAC40 & LL & 38.41 & 33.57 & 41.98 & 37.69 & 41.81 & \\
& MLE fit & 2.38 & 6.6 & 2.19 & 0.79 & $6,0.79$ & USA/ France \\
& AIC & 100.2 & 86.45 & 108.01 & 99.44 & 103.8 & \\
RSP500/ RIBEX35 & LL & 52.19 & 45.27 & 56.05 & 50.73 & 53.99 & USA/ Spain \\
& MLE fit & 1.58 & 4.78 & 1.79 & 0.66 & $40,0.66$ & US \\
& AIC & 55.98 & 52.83 & 62.23 & 62.87 & 60.535 & \\
& LL & 30.04 & 28.47 & 33.16 & 32.45 & 32.31 & \\
\hline
\end{tabular}

Source: Present Research Findings based on the Output of Model Risk Software 
RASEKHI \& NABAVI, Journal of Business Strategy, Finance and Management,

Vol. 02(1 \& 2) 89-101 (2021)

Table 12: Proper copula

\begin{tabular}{lc}
\hline Capula & Country \\
\hline Normal & USA/ South Korea \\
t- Student & USA/ England \\
Gumbel & USA/ Germany \\
Gumbel & USA/ Netherlands \\
Gumbel & USA/ France \\
Normal & USA/ Spain \\
\hline
\end{tabular}

Source: Present Research Findings based on the Output of Model Risk Software

Table 13: Rank correlation coefficient before introducing futures

\begin{tabular}{cccccc}
\hline Clayton & Frank & Gumbel & Normal & t-student & Country \\
\hline 0.34 & 0.35 & 0.34 & 0.44 & 0.44 & USA/ South Korea \\
0.53 & 0.55 & 0.53 & 0.56 & 0.58 & USA/ England \\
0.57 & 0.52 & 0.53 & 0.54 & 0.55 & USA/ Germany \\
0.49 & 0.46 & 0.45 & 0.52 & 0.51 & USA/ Netherlands \\
0.55 & 0.52 & 0.53 & 0.57 & 0.59 & USA/ France \\
0.45 & 0.46 & 0.51 & 0.47 & 0.48 & USA/Spain \\
\hline
\end{tabular}

Source: Present Research Findings based on the Output of Model Risk Software

Table 14: Rank correlation coefficient after introducing futures

\begin{tabular}{lccccc}
\hline Clayton & Frank & Gumbel & Normal & t-student & Country \\
\hline 0.32 & 0.31 & 0.3 & 0.34 & 0.36 & USA/ South Korea \\
0.52 & 0.53 & 0.51 & 0.5 & 0.56 & USA/ England \\
0.55 & 0.51 & 0.5 & 0.56 & 0.56 & USA/ Germany \\
0.44 & 0.45 & 0.41 & 0.51 & 0.49 & USA/ Netherlands \\
0.52 & 0.51 & 0.5 & 0.57 & 0.56 & USA/ France \\
0.4 & 0.42 & 0.43 & 0.42 & 0.45 & USA/Spain \\
\hline
\end{tabular}

Source: Present Research Findings based on the Output of Model Risk Software

Table 15: Results of the research hypothesis test

\begin{tabular}{cc}
\hline p- value & Country \\
\hline 0.004 & United States of America/ South Korea \\
0.008 & United States of America/ England \\
0.003 & United States of America/ Germany \\
0.043 & United States of America/ Netherlands \\
0.032 & United States of America/ France \\
0.004 & United States of America/ Spain \\
\hline
\end{tabular}

Source: Present Research Findings based on the Output of Model Risk Software 
In the research hypothesis, $\mathrm{H}_{0}$ indicates that the futures haven't the negative effect on financial contagion. The test results are presented in table 15. The value of $p$-value in all pair of series based on the results of the hypothesis test in this table is less than 0.05 . As a result, the null hypothesis based on the ineffectiveness of the futures on financial contagion is not accepted, and therefore the $\mathrm{H}_{1}$, namely, the peresence of financial contagion with a probability of $95 \%$ is approved.

\section{Conclusion}

The main purpose of this study is to test the effect of the derivatives on financial contagion in the developed countries of France, Germany, South Korea, Spain, the Netherlands and the United Kingdom, considering the United States as the source of the crisis. The starting point for the crisis is October 2008, but we assumed that the crisis period has begun since September 2008 for more confidence in modeling, and therefore the pre-crisis period is January 2007 to August 2008. The hypothesis of the present study is that the future contracts reduce the financial contagion in developed countries. To test the effect of the futures on the financial contagion, the filtered returns were extracted only for the crisis period with the ARMAGARCH model, and then the Copula dependence parameters for the crisis period were estimated.

The results of this research showed that the copula dependence parameter as well as the Kendall rank correlation coefficient decreased with the introducingfutures. This means a negative effect of the future contractson the stock market in developed countries.
According to the results, the difference between the rank correlation coefficient before introducing the derivatives with the rank correlation coefficient after introducing the derivative instrument $(\Delta \underline{\tau})$ is very little in the United States/Germany. This means that the rank correlation coefficient did not change much and fell less than other countries after introducing the derivatives. Therefore, the derivatives did not have a significant impact on the financial contagion in Germany than other countries. is more in the United States /United Kingdom than the others. Therefore, derivatives had a significant impact on the financial contagion of England than other countries. It can be said that the effectiveness of the derivatives on the contagion in the selected countries depends on the geographical location, pure and financial channels, the economic infrastructures, the behavior of investors, the relationship with global financial markets, and so on.

\section{Acknowledgement}

This research received no specific grant from any funding agency in the public, commercial, or notfor-profit sectors.

\section{Funding}

The author(s) received no financial support for the research, authorship, and/or publication of this article.

\section{Conflict of Interest}

There is no conflict of interest

\section{References}

1. Boyer, B., and Loretan, M. (1999). Pitfalls in tests for changes in correlations. International Finance Discussion paper, 597, 10-28.

2. Bollerslev, T. (1986). Generalized auto regressive conditional heteroskedasticity. Journal of Econometrics, 31, 307-327.

3. Bae, K; Karolyi, A., and Stulz, R.M. (2003). A New Approach to Measuring Financial Contagion. Review of Financial Studies, 16, 717-763.
4. Berkes,I., and Horv, L. (2003). Asymptotics For GARCH Squared Residual Correlations. Economics and Finance Worker, 19, 515-540.

5. Cox, C.C. (1976). Future Trading and Market Information. Journal of Political Economics, 84, 1215-1237.

6. Eichengreen, B., and Mody, A. (2011). International Financial Crises and the Multilateral Response: What the Historical Record Shows. NBER Working Paper, 

Vol. 02(1 \& 2) 89-101 (2021)

17361, 35-72.

7. Figlewski, S. (1981). Futures Trading and Volatility in the GNMA Market. Journal of Finance, 36, 445-457.

8. Gandolfo, G. C. (2016). International Finance and Open-Economy Macroeconomics. Chap (16). Second Edition.

9. Haugh, M. (2016). An Introduction to Copulas. Quantitative Risk Management journal. 5, 231-243.

10. Horta, P., and Vieira, I. (2008). Contagion effects of the US Subprime Crisis on Developed Countries. CEFAGE-UE Working Paper. Available at: file:///C:/Users/SahandPc/Downloads/2008_08.pdf.

11. Imen, M., and Abidi, R. (2012). A Dynamic Analysis of Financial Contagion: The Case of the Subprime Crisis. Journal of Business Studies Quarterly, 4, 11-27.

12. Islam, M., andChakraborti, J. (2015). Futures and forward contract as a route of hedging the risk. Risk Governance and Control Financial Markets \& Institutions, 5, 68-79.

13. Joe, H. (1997). Multivariate Models and Dependence Concepts. Mathematical Reviews, 18, 481-501.

14. Jacobsen, B. (2010). Currency, credit, confidence and bubbles. The North American Journal of Economics and Finance. 17 ,1653-1655.

15. Kuusk, A.,and Tripathi, T. (2011).Financial Contagion of the 2008 Crisis: Is There Any Evidence of Financial Contagion from the US to The Baltic States. Eastern Journal of European Studies, 2, 61-76.

16. Kim, H. Y. (2013). Statistical notes for clinical researchers: assessing normal distribution using skewness and kurtosis. Open lecture on statistics. Available at: https://www.rde. ac/Synapse/Data/PDFData/2185RDE/rde38-52.pdf

17. Mollah, S., and Zafirov, G. (2014). Financial Market Contagion During the Global Financial Crisis. CITR Electronic Working Paper Series, 5, 71-86.

18. McLear, M., and Chang, C. (2013). Conditional correlations and volatility spillovers between crude oil and stock index returns. The North American Journal of Economics and Finance, 25, 116-138.

19. Masson, P. (1999). Contagion:macroeconomic models with multiple equilibria. Journal of International Money and Finance, 18, 587-602.

20. Mallikarjunappa, T., and Afsal E. M. (2008). The Impact of Derivatives on Stock Market Volatility: A Study of the Nifty Index. Journal of Economics and Finance ,4 , 42-66.

21. Nelsen, R.B. (1999). An Introduction to Copulas. Mathematical Reviews, 16, 53-75.

22. Powers, M.J. (1970). Does Futures Trading Reduce Price Fluctuations in the Cash Markets? American Economic Review, 60, 460-464.

23. Pilar, C., and Rafael, S. (2001). Does Derivatives Trading Destabilize the Underlying Assets? Evidence from the Spanish Stock Market. Applied Economics Letters, 9, 107-110.

24. Patton, A.J. (2002). Modelling time-varying exchange rate dependence using the conditional copula. Working paper, UCSD, 1, 102-104.

25. Pritsker, M., and Michael, S. (2000). Improving Grid-Based Methods for Estimating Value at Risk of Fixed-Income Portfolios. FEDS working paper, 144, 2000-2025

26. Rodriguez, J. (2007). Measuring Financial Contagion: A Copula Approach. Journal of Empirical Finance, 14, 300-345.

27. Ray, k., and Panda, A. K. (2011). The impact of derivatives trading on spot market volatility: Evidence from indian derivatives market. Interdisciplinary Journal of Research in Business, 1,117-131.

28. Rossi, L., and Daigler, R. T. (2006). A Portfolio of Stocks and Volatility. Journal of Investing, 1, 99-106.

29. Sklar, A. (1973). Random Variables, Joint Distribution Functions and Copulas. Kybernetika, 9, 450- 460.

30. Siedlecki, L., andPapla, D. (2016). Conditional correlation coefficient as a tool for analysis of contagion in financial markets and real economy indexes based on the synthetic ratio. Procedia, Social and Behavioral Sciences 22, 452 - 461.

31. Souri, A. (2013). Econometrics with the use of Eviews, Cultural Studies Publication.

32. Singh, S., and Tripathi L. K. (2015). Impact of Derivative Trading on Currency Market Volatility in India. Global Journal of 

Vol. 02(1 \& 2) 89-101 (2021)

Multidisciplinary Studies, 4, 226-238.

33. Schwarz, T. (1991). Dynamic Efficiency and Price Leadership in Stock Index and Future Market. Journal of Futures Market, 11, 669-683.

34. Shenbagaraman, P. (2003). Do Futures and Options Trading Increase Stock Market Volatility? NSE Working Paper, 22, 115-158.

35. Schmidt, T. (2006). Correlation with Copulas. European Economic Review, 38, 1120-1141.

36. Stein, E., and Stein, J. (1991). Stock price distribution with stochastic volatility: An analytic approach. The Review of Financial Studies, 4, 727-752.

37. Shastri, L.B. (2017). Copula Approach: Correlation Between Bond Market and Stock Market, Between Developed and Emerging Economies. International Journal For Innovative Research In Multidisciplinary Field, 3, 203-208

38. Trivedi, P. K., and Zimmer, M. (2005). Copula
Modeling: An Introduction for Practitioners. Journal of International Money and Finance, 42, 141- 152.

39. Wolf, H.C. 1999 Transitional Strategies: Choices and Outcomes, Princeton Studies in International Finance, 85, 1-30.

40. World bank. (2016). Definitions of Contagion. Available at: http://go.worldbank.org/ JIBDRK3YC0

41. Wiggins, R. Z.;Piontek, T., andMetrick, A. (2014). The Lehman Brothers Bankruptcy A: Overview. Yale Program on Financial Stability Case Study, 3A-V1.

42. Website of Investing Statistical Database. Various Years, Available at: https://www. investing.com.

43. Seth, N. and Panda, L. (2018). Financial contagion: review of empirical literature, Qualitative Research in Financial Markets, 10 (1): 15-70. 